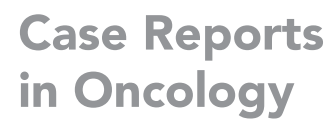

Case Reports

in Oncology

\title{
Primary Pleural Extranodal Marginal Zone Lymphoma Presenting as Bilateral Chylothorax
}

\author{
Thushara Paul ${ }^{a}$ Dhiraj Kumar Yadav ${ }^{a}$ Mohamed Alhamar ${ }^{b}$ \\ Vrushali Dabak ${ }^{a}$ \\ aDepartment of Hematology and Oncology, Henry Ford Health System, West Bloomfield, \\ MI, USA; bepartment of Pathology and Laboratory Medicine, Henry Ford Health System, \\ West Bloomfield, MI, USA
}

\author{
Keywords \\ Chylothorax · Extranodal marginal zone lymphoma $\cdot$ Pleural effusion
}

\section{Abstract}

Here we describe a case of pleural extranodal marginal zone lymphoma presenting as bilateral chylothorax which has not been reported in the literature prior to this. Primary pleural lymphomas are a rare entity most commonly associated with chronic infections, autoimmune conditions or long-standing pyothorax which were not seen in this case. Chylous pleural effusions in this patient were successfully managed with chemotherapy for the underlying lymphoma.

\section{Introduction}

Primary pleural lymphomas are rare. Extranodal marginal zone lymphomas (EMZL) arise from mucosa-associated lymphoid tissue and are most commonly associated with chronic inflammation caused by infections and autoimmune conditions. Pleural marginal zone lymphoma is also thought to be related to chronic pleural inflammation which could be seen in some long-standing lung infections.

Chylothorax has been reported in some lymphoproliferative disorders; however, this has not been reported in pleural EMZL. Most of the reported cases of chylothorax are due to 


\section{Case Reports in Oncology}

Fig. 1. CT scan of the chest showing bilateral moderate pleural effusions.

Fig. 2. Pleural biopsy showing subpleural dense lymphoid proliferation in a diffuse distribution; lymphoid cells are predominantly small, mature lymphoid cells with hyperchromatic nuclei and pale/ clear cytoplasm, imparting a "monocytoid" appearance (HE. $\times 4)$.

\begin{tabular}{l|l}
\hline Case Rep Oncol 2020;13:929-934 \\
\hline DOI: 10.1159/000508704 & $\begin{array}{l}\text { ○ 2020 The Author(s). Published by S. Karger AG, Basel } \\
\text { www.karger.com/cro }\end{array}$ \\
\hline
\end{tabular}

Paul et al.: Chylothorax in Pleural Extranodal Marginal Zone Lymphoma
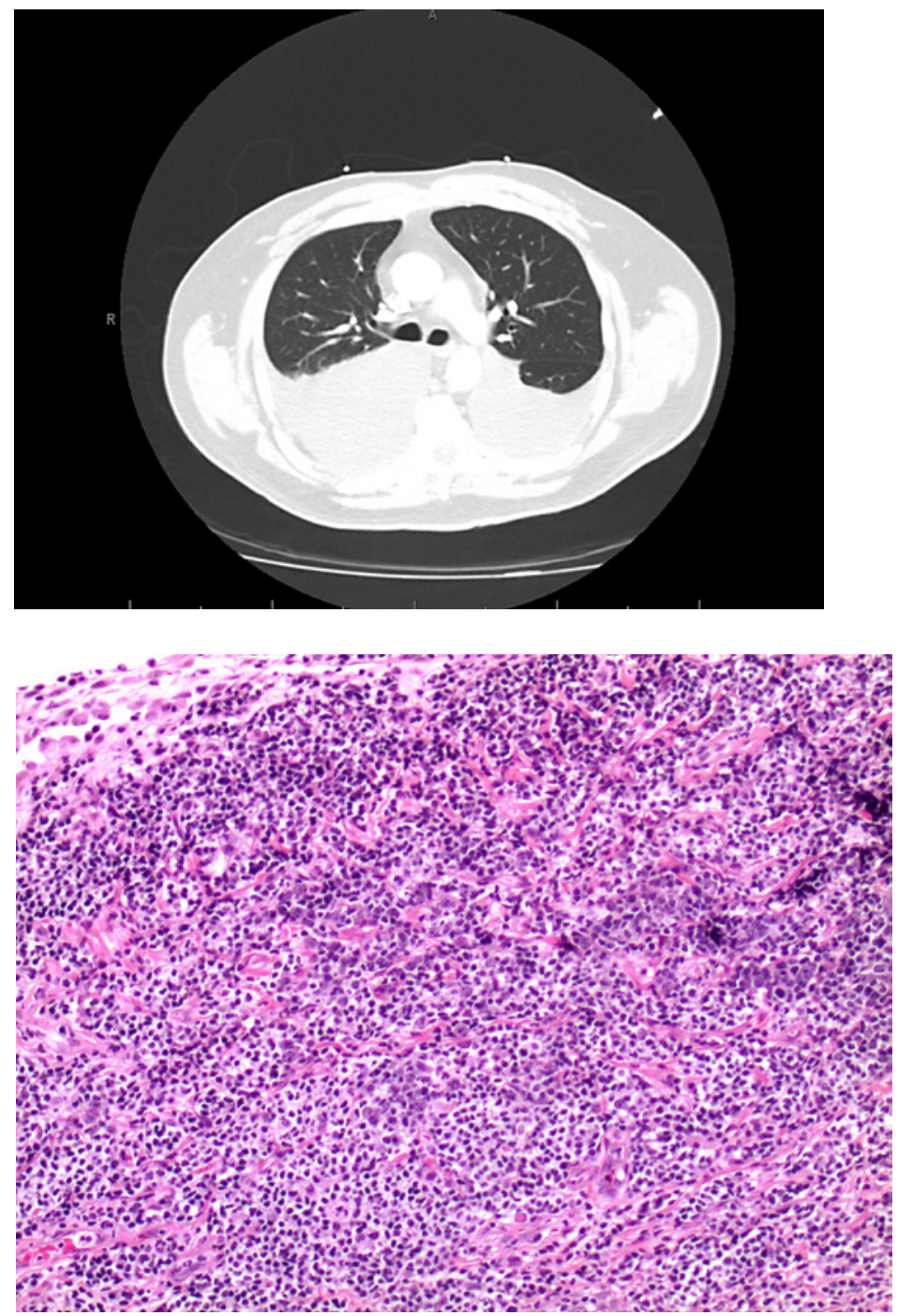

compression or direct involvement of the thoracic duct or lymphatics. We present a rare case of pleural EMZL presenting as bilateral chylothorax without any direct invasion of the thoracic duct.

\section{Case Presentation}

A 62-year-old previously healthy male presented with a history of progressive dyspnea and weight loss for the last couple of months. Initial evaluation included a computerized tomography (CT) scan of the chest which revealed large bilateral pleural effusions with compressive atelectasis. Subsequently, he underwent bilateral thoracentesis with removal of pleural fluid, which showed turbid to bloody pleural fluid with white cell count of more than $1,200 / \mathrm{mm}^{3}$ on fluids from both sides. White cells were predominantly lymphocytes (67-69\%) and the triglyceride level in the fluid was $531 \mathrm{mg} / \mathrm{dL}$ suggestive of chylothorax. Further studies of the fluid revealed elevated protein, high $\mathrm{pH}$ and low LDH typical of chylous pleural fluid. Pleural fluid cytology and culture were negative. CT scans of the chest and abdomen did not reveal any evidence of lymphadenopathy or hepatosplenomegaly. 


\section{Case Reports in Oncology}

Fig. 3. Bone marrow biopsy showing juxta-trabecular lymphoid clusters in a background of trilineage hematopoiesis; lymphoid cells are small with atypical irregular nuclei (HE. ×10).

\begin{tabular}{l|l}
\hline Case Rep Oncol 2020;13:929-934 \\
\hline DOI: 10.1159/000508704 & $\begin{array}{l}\text { @ 2020 The Author(s). Published by S. Karger AG, Basel } \\
\text { www.karger.com/cro }\end{array}$ \\
\hline
\end{tabular}

Paul et al.: Chylothorax in Pleural Extranodal Marginal Zone Lymphoma

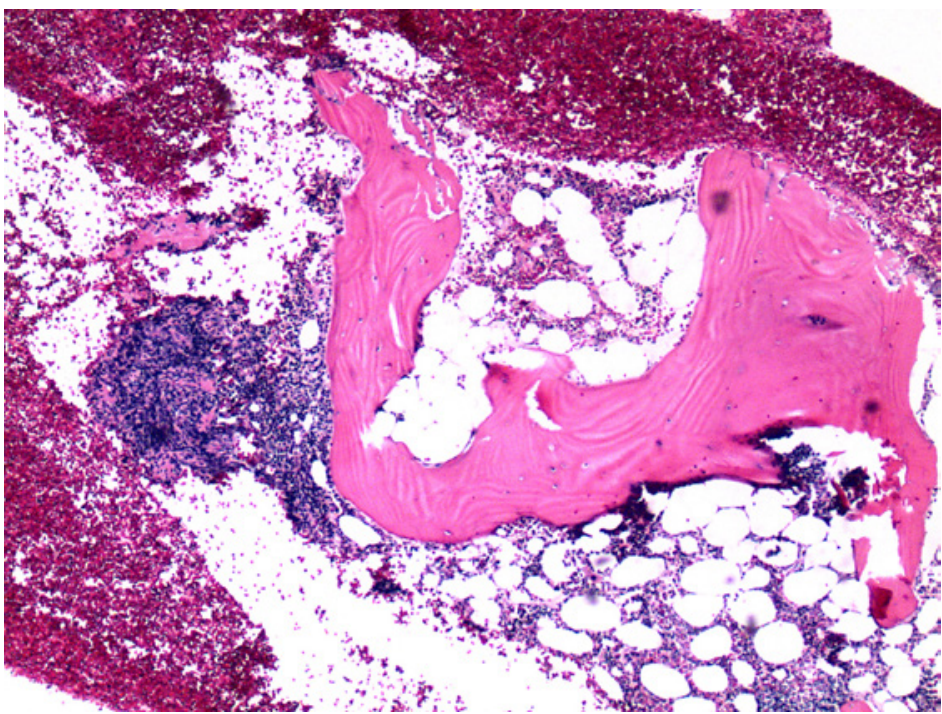

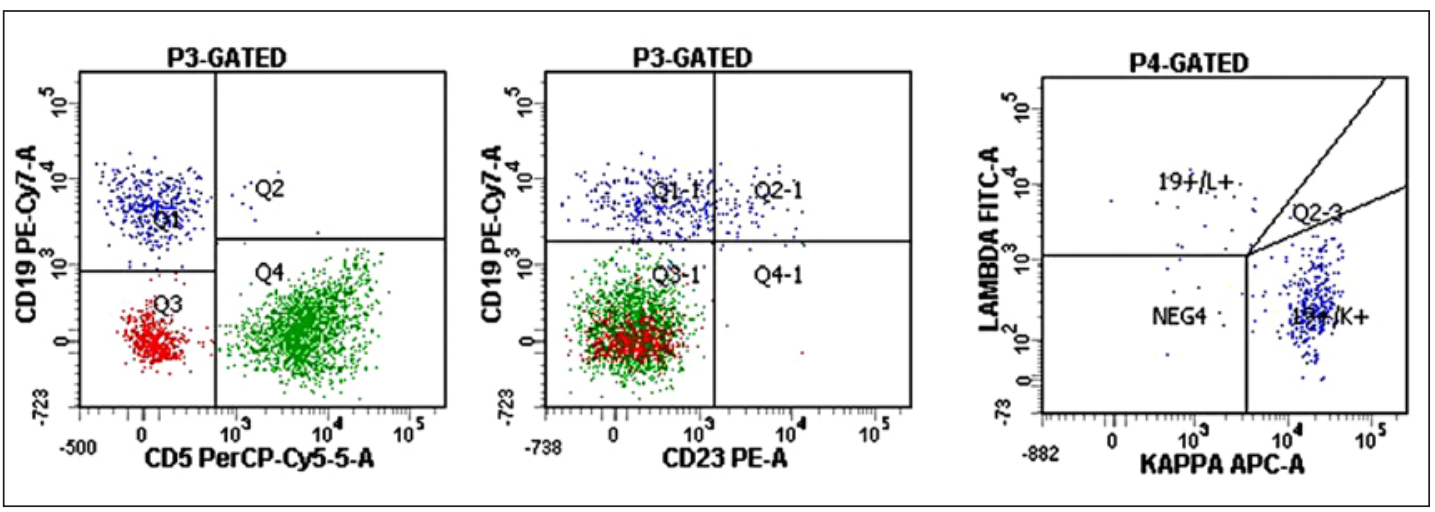

Fig. 4 Flow cytometry plots of the pleura showing B cells which are CD19-positive, CD5-negative, CD23-negative and kappa light chain restricted.

The patient showed improvement in his breathing after thoracentesis and was discharged home with outpatient follow-up. However, 2 weeks later, he presented to the emergency department again with worsening dyspnea and was found to have recurrence of bilateral pleural effusions (Fig. 1).

Subsequently, bilateral chest tubes were placed. Pleural fluid chemistry was similar to previous findings. White cell count was consistently more than $1,200 / \mathrm{mm}^{3}$ in the pleural fluid and triglyceride levels were more than $400 \mathrm{mg} / \mathrm{dL}$ in repeated testing as well. Pleural fluid cytology remained negative in all the analyses. The patient underwent video-assisted thoracoscopic surgery with pleural biopsy, which revealed CD19-positive, CD5- and CD23-negative, kappa light chain restricted low-grade B-cell non-Hodgkin lymphoma consistent with extranodal marginal zone lymphoma (Fig. 2, 4).

There was no evidence of human herpes virus-8 (HHV-8) in the cells. Bone marrow biopsy also showed CD5- and CD23-negative B-cell lymphoproliferative disorder consistent with marginal zone lymphoma (Fig. 3). Chromosome and fluorescent in-situ hybridization analyses (FISH) were normal.

The patient was started on chemotherapy (bendamustine and rituximab). Bilateral chest tubes were removed after the first cycle of chemotherapy without any re-accumulation of 
Fig. 5. CT scan showing improvement in bilateral pleural effusions after chemotherapy.

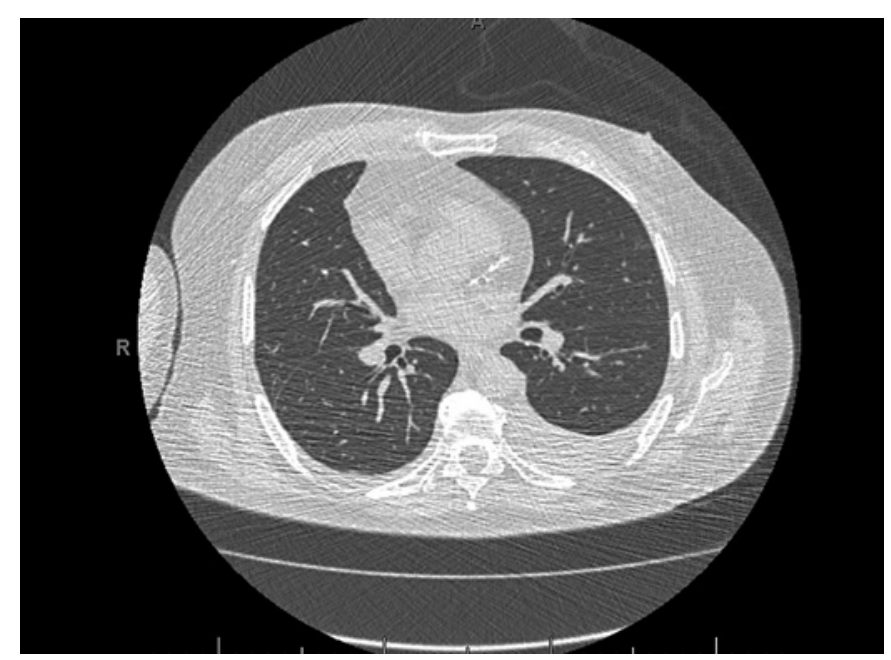

chylothorax. PET scan done after six cycles of chemotherapy showed no hypermetabolism to suggest active malignancy and improvement in pleural effusions. Subsequent CT scans also confirmed the finding of decreasing bilateral pleural effusions (Fig. 5). The patient has been doing well and did not require any thoracentesis for his pleural effusions after being started on chemotherapy.

\section{Discussion}

EMZL or mucosa-associated lymphoid tissue lymphoma is a relatively uncommon clonal B-cell neoplasm which comprises only $5-10 \%$ of all non-Hodgkin lymphoma and arises in various epithelial tissues, mostly gastrointestinal, salivary glands and cutaneous tissues. Lung involvement more commonly presents as lung nodules which could be pleural based or as air space consolidation $[1,2]$. Primary pleural involvement is very rare but has been reported in a few case reports [3-8]. More common types of primary pleural non-Hodgkin lymphomas are primary effusion lymphoma associated with HHV-8 and pyothorax-associated lymphoma often associated with tuberculosis or Epstein-Barr virus. Our patient had no evidence of HHV-8 infection in the nuclei of malignant cells nor was there any preceding history of long-standing pyothorax. EMZL is mostly related to chronic inflammation due to viral or bacterial infections or occurs in the setting of autoimmune diseases. The case we are reporting was unusual in this aspect too as there was no detectable association with any infection or autoimmune disorder.

The aforementioned case also had bone marrow involvement which makes it only the second reported pleural EMZL presenting with bone marrow spread. Gomyo et al. [9] have previously reported a case of pleural EMZL with spread to the bone marrow in a patient with chromosomal translocation 14;18. Bone marrow involvement has also previously been noted with CD5+ low-grade EMZL; however, B cells in our case were CD5-negative [10]. EMZL cells typically express B-cell antigens like CD19, C20, CD79a but are usually negative for CD10 and CD5. This is important in differentiating from other small B cell lymphomas, which can present in a similar fashion like small lymphocytic lymphoma, mantle cell lymphoma and follicular lymphoma. Chromosomal abnormalities may also be frequently encountered in EMZL patients; however, there is no single chromosome change that is specific to the condition. No chromosomal aberration could be identified in our case.

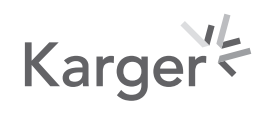


The other peculiar finding in this case was the presentation of EMZL as chylothorax, which has not been reported before. The major etiology of non-traumatic chylothorax is malignancy of which lymphoma is one of the most common causes [11]. Indolent lymphomas like follicular and mantle cell lymphoma have been reported to cause chylothorax more often than the aggressive ones like diffuse large B-cell lymphoma [12]. Other lymphoprofilerative disorders like chronic lymphocytic leukemia have also been implicated in the etiology of chylothorax [13].

Direct invasion or compression of the thoracic duct is the more common mechanism of chylothorax caused by lymphoproliferative disorders. This was, however, not present in our case and chylothorax was bilateral. We assumed that the direct stimulation of the lymphatic ducts due to the involvement of the pleura leading to rupture or oozing of chyle must have been responsible for the development of chylothorax in this case. Treatment of the underlying lymphoma with chemotherapy led to a significant improvement of chylothorax in this case and did not require any surgical intervention or radiation therapy.

\section{Statement of Ethics}

Written informed consent was provided by the patient for publication of the case report and all the images in the manuscript.

\section{Conflict of Interest Statement}

The authors declare that they have no conflicts of interest.

\section{Funding Sources}

The authors did not receive any funding for this article.

\section{Author Contributions}

All authors were involved in the preparation of this article. All authors have read and approved the final manuscript.

\section{References}

1 Imai H, Sunaga N, Kaira K, Kawashima O, Yanagitani N, Sato K, et al. Clinicopathological features of patients with bronchial-associated lymphoid tissue lymphoma. Intern Med. 2009;48(5):301-6.

2 Kodama K, Yokose T, Takahashi K, Minami H, Nagai K, Matsuno Y, et al. Low-grade B-cell lymphoma of mucosaassociated lymphoid tissue in the lung: a report of a case with pleural dissemination. Lung Cancer. 1999;24(3): $175-8$.

3 Motta G, Conticello C, Amato G, Moschetti G, Colarossi C, Cosentino S, et al. Pleuric presentation of extranodal marginal zone lymphoma of mucosa associated lymphoid tissue: a case report and a review of the literature. Int J Hematol. 2010;92(2):369-73.

4 Mitchell A, Meunier C, Ouellette D, Colby T. Extranodal marginal zone lymphoma of mucosa associated lymphoid tissue with initial presentation in the pleura. Chest. 2006;129(3):791-4.

5 Hirai S, Hamanaka Y, Mitsui N, Morifuji J, Sutoh M. Primary malignant lymphoma arising in the pleura without preceding long-standing pyothorax. Ann Thorac Cardiovasc Surg. 2004;10(5):297-300.

6 Ahmad H, Pawade J, Falk S, Morgan JA, Balacumaraswami L. Primary pleural lymphomas. Thorax. 2003; 58(10):908-9. 
7 Malek A, Lee JC. Extranodal Marginal Zone Lymphoma of Mucosa Associated Lymphoid Tissue Arising in The Pleura. Ann Pathol Lab Med. 2015;2(2):66-70.

8 Nakarsuka S, Nagano T, Kimura H, Hanada S, Inoue H, Iwata T. Extranodal marginal zone lymphoma of mucosaassociated lymphoid tissue type arising in the pleura with pleural fibrous plaques in a lathe worker. Ann Diagn Pathol. 2012;16(3):224-9.

9 Gomyo H, Kajimoto K, Maeda A, Mizuno I, Funada Y, Koizumi T, et al. t(14;18)(q32;q21)-bearing pleural MALT lymphoma with IgM paraproteinemia: Value of detection of specific cytogenetic abnormalities in the differential diagnosis of MALT lymphoma and lymphoplasmacytic lymphoma. Hematology. 2007;12(4):315-8.

10 Ferry JA, Yang WI, Zukerberg LR, Wotherspoon AC, Arnold A, Harris NL. CD5+ extranodal marginal zone B-cell (MALT) lymphoma. A low grade neoplasm with a propensity for bone marrow involvement and relapse. Am J Clin Pathol. 1996;105(1):31-7.

11 Doerr CH, Allen MS, Nichols FC 3rd, Ryu JH. Etiology of Chylothorax in 203 Patients. Mayo Clin Proc. 2005; 80(7):867-70.

12 Pospiskova J, Smolej L, Belada D, Simkovic M, Motyckova M, Sykorova A, et al. Experiences in the treatment of refractory chylothorax associated with lymphoproliferative disorders. Orphanet J Rare Dis. 2019;14(1):9.

13 Teng CL, Li KW, Yu JT, Hsu SL, Wang RC, Hwang WL. Malignancy-associated chylothorax: a 20-year study of 18 patients from a single institution. Eur J Cancer Care. 2012;21(5):599-605. 